Pesq. Vet. Bras. 35(4):377-384, abril 2015 DOI: $10.1590 /$ S0100-736X2015000400011

\title{
Análise comparativa da morfometria do casco de bovinos das raças Nelore, Curraleira e Pantaneira e de bubalinos e sua relação com a etiopatogenia das enfermidades digitais ${ }^{1}$
}

\author{
Luiz A.F. Silva ${ }^{2 *}$, Suyan B.S. Campos ${ }^{3}$, Rogério E. Rabelo ${ }^{4}$, Valcinir A.S. Vulcani ${ }^{4}$, \\ Antônio Dionísio F. Noronha Filho ${ }^{5}$ e Sabrina L.R. de Freitas ${ }^{6}$
}

\begin{abstract}
Silva L.A.F., Campos S.B.S., Rabelo R.E., Vulcani V.A.S., Noronha Filho A.D.F. \& Freitas S.L.R. 2015. [Morfometric comparative analysis of the hoof of Nelore, Pantaneira and Curraleira breeds of cattle and buffaloes and their relationship with the pathogenesis of digital diseases.] Análise comparativa da morfometria do casco de bovinos das raças Nelore, Curraleira e Pantaneira e de bubalinos e sua relação com a etiopatogenia das enfermidades digitais. Pesquisa Veterinária Brasileira 35(4):377-384. Setor de Clínica e Cirurgia, Departamento de Medicina Veterinária, Escola de Veterinária e Zootecnia, Universidade Federal de Goiás, Campus II Samambaia, Goiânia, GO 74001-970, Brazil. E-mail: prof_ufg.dmv@hotmail.com

Morfometric studies of bovine and buffalo digits can help to understand the etiopathogeny of digital diseases. This study described morphometric characteristics of digits of Curraleira (Bos taurus), Pantaneira (Bos taurus) Nelore (Bos indicus) breeds of cattle and Murrah buffalo (Bubalus bubalis) and stablish possible relation among the parameters and digital infirmities. Were used ten animals of each breed and specie. Two limbs were evaluated, a toracic and a pelvic, in a total of 80 distal limbs. Morphometric measurements were obtained using a graduated paquimeter and angles using a metallic protactor. The main parameters evaluated were hoof dorsal angle (A), dorsal wall length (B), heel height (C), toe height (D), hoof length (E), hoof diagonal hoof (F), lateral digit width (H), medial digit width (I) and medial digit length (J). For results averages comparison among breeds were used Tukey test $(p<0,05)$. Multivariate analysys for graphic representations of canonic variables was used to express similarity of measures studied among groups, using $\mathrm{R}$ software. Results shows tha bubaline present higher morphometric measures for the variables B, C, D, E, F, G, H, I and J, only for variable A presented lower measures comparing the bovine breeds studied. There is similarity between the three breeds of cattle studied about toe height (D), lateral digit width (G) and medial digit width $(\mathrm{H})$, which differed of values observed in buffalo. It was concluded that digital morphometry can influence the occurence of digital infirmities, but doesn't act as an isolated factor, needing interaction of other structural, environmental and management factors for its occurence.
\end{abstract}

INDEX TERMS: Cattle, buffalo, hoof, digit, digital disease, measures.

\footnotetext{
${ }^{1}$ Recebido em 17 de fevereiro de 2014.

Aceito para publicação em 26 de fevereiro de 2015.

${ }^{2}$ Docente do Departamento de Medicina Veterinária, Setor de Cirurgia, Escola de Veterinária e Zootecnia (EVZ), Universidade Federal de Goiás (UFG), Campus II Samambaia, Cx. Postal 131, Goiânia GO 74001-970, Brasil.*Autor para correspondência: prof_ufg.dmv@hotmail.com

${ }^{3}$ Médica Veterinária, Docente da Universidade Paulista (Unip), Cirurgia de Grandes Animais, Campus II Samambaia, Cx. Postal 131, Goiânia GO 74001-970.E-mail: suyanvet@gmail.com

${ }^{4}$ Docente da Universidade Federal de Goiás (UFG), Curso de Medicina
}

Veterinária, Setor de Cirurgia de Grandes Animais, Campus Jataí, Unidade Jatobá, BR-364 Km 192, № 300, Parque Industrial, Jatobá, GO 75801-615. E-mails: rabelovet@yahoo.com.br, aloisiosv@hotmail.com

${ }^{5}$ Doutorando em Ciência Animal, Departamento de Medicina Veterinária, Setor de Cirurgia, Escola de Veterinária e Zootecnia (EVZ) Universidade Federal de Goiás (UFG), Campus II Samambaia, Cx. Postal 131, Goiânia G0 74001-970. E-mail: dionisiofnf@hotmail.com

${ }^{6}$ Mestranda em Ciência Animal, Departamento de Medicina Veterinária, Setor de Cirurgia, EVZ-UFG, Campus II Samambaia, Cx. Postal 131, Goiânia G0 74001-970. E-mail: sabrina_medvet@hotmail.com 
RESUMO.- 0 estudo morfométrico dos dígitos de bovinos e bubalinos pode colaborar para o entendimento da etiopatogenia das enfermidades podais. Este estudo objetivou descrever as características morfométricas dos dígitos de bovinos das raças Curraleira (Bos taurus), Pantaneira (Bos taurus), Nelore (Bos indicus) e de bubalinos (Bubalus bubalis) da raça Murrah e estabelecer possível relação entre tais medidas e a ocorrência de enfermidades digitais. Na pesquisa foram utilizados dez animais, saudáveis, de cada raça e espécie. Foram avaliados dois membros de cada animal, sendo um torácico e outro pélvico, totalizando 80 extremidades distais. As medidas morfométricas foram obtidas com auxílio de um paquímetro mecânico graduado e os ângulos das pinças conferidos por meio de transferidor metálico. Os principais parâmetros digitais avaliados foram o ângulo dorsal do casco (A), comprimento da parede dorsal (B), altura do talão (C), altura da pinça (D), comprimento do casco (E), comprimento diagonal do casco (F), largura do dígito lateral $(\mathrm{G})$, largura do dígito medial $(\mathrm{H})$, comprimento do dígito lateral (I) e comprimento do dígito medial (J). Para a comparação de médias dos resultados obtidos entre as raças foi utilizado o teste de Tukey $(p<0,05)$. A análise multivariada para as representações gráficas das variáveis canônicas foi empregada para expressar a similaridade das medidas estudadas entre os grupos, no qual se utilizou o software R. Os resultados revelaram que os bubalinos apresentam as maiores medidas morfométricas para as variáveis B, C, D, E, F, G, H, I e J e apenas na variável A apresentaram medidas inferiores entre as diferentes raças de bovinos estudadas. Existe similaridade entre as três raças de bovinos estudadas em relação às variáveis, altura da pinça (D), largura do dígito lateral (G) e largura do dígito medial $(\mathrm{H})$ as quais se distanciam dos valores encontrados para essas variáveis nos bubalinos, Concluiu que a morfometria digital pode influenciar na ocorrência de enfermidades digitais, mas não age como fator isolado, necessitando da interação com outros fatores estruturais, ambientais e de manejo para a manifestação dessas doenças.

TERMOS DE INDEXAÇÃO: Gado, búfalo, casco, dígito, enfermidade digital, medidas.

\section{INTRODUÇÃO}

O Brasil possui um contingente de 212.798 .000 bovinos e 1.277 milhões de cabeças de bubalinos (IBGE 2012) tornando esse seguimento produtivo bastante promissor. Muitos avanços alcançados na bovinocultura têm contribuído para aumentar a produção dos criatórios, mas tornam os animais mais vulneráveis à doenças como as enfermidades digitais (Rodrigues et al. 2013). Para Demirkan, Murray \& Carter (2000), Leão (2006) e Greenough (2007), Archer et al. (2010) e Huxley (2012) as enfermidades digitais constituem um dos principais problemas do aparelho locomotor dos bovinos, resultando em dificuldade de locomoção, baixa ingestão de alimento, além de afetar a produção. Para minimizar os prejuízos ocasionados pelas enfermidades podais, Melo (2005) recomendou associar a melhoria genética dos rebanhos a intensificação de medidas de controle sanitário e Silva et al. (2001) sugeriu conhecer os fatores envolvidos na gênese dessas enfermidades.

Segundo Greenough (2007) e Nuss et al. (2011) alguns aspectos morfológicos digitais estão relacionados a susceptibilidade digital às diferentes enfermidades. Para Túlio (2006) existe alta a correlação entre a genética e a ocorrência de distúrbios nos cascos e recomendou ampliar os estudos envolvendo as características anatômicas dos cascos da espécie bubalina, que em tese, minimizam a ocorrência de enfermidades digitais. Mas apesar dos indícios, são poucas as informações científicas que estabelecem relação entre as medidas morfométricas dos dígitos de diferentes raças de bovinos e da espécie bubalina com as enfermidades digitais. Sobre o assunto acredita-se que raças naturalizadas como a Curraleira e a Pantaneira e a espécie bubalina, por serem consideradas resistentes as doenças digitais, não podem ser negligenciadas nessa modalidade de pesquisa.

No presente trabalho avaliou-se características morfométricas dos dígitos de três raças brasileiras de bovinos e de uma raça de bubalinos na tentativa de se estabelecer possível relação entre tais medidas e a ocorrência de enfermidades digitais.

\section{MATERIAL E MÉTODOS}

A pesquisa foi desenvolvida na Escola de Veterinária e Zootecnia da Universidade Federal de Goiás (EVZ-UFG) após aprovação do projeto pelo Comitê de Ética em Pesquisa da UFG, protocolo $\mathrm{N}^{\circ}$ 189/11. No estudo avaliaram-se extremidades distais dos membros locomotores de 40 animais distribuídos em três raças de bovinos e uma de bubalino, do sexo masculino e com idades entre 24 e 36 meses. Os animais foram alocados de acordo com a raça ou espécie em quatro grupos (GI, GII, GIII e GIV), contendo dez exemplares em cada. 0 grupo GI foi constituído por animais da raça Nelore (Bos indicus), no GII distribuíram-se animais da raça Pantaneira (Bos taurus) e o GIII foi formado por bovinos da raça Curraleira (Bos taurus). No grupo GIV foram alocados búfalos da raça Murrah (Bubalus bubalis).

Após a aquisição, os animais foram mantidos durante 120 dias em regime intensivo na Fazenda Tomé Pinto da EVZ-UFG, no município de São Francisco de Goiás/GO, latitude 1555'49.0732”S, longitude $49^{\circ} 15^{\prime} 49.4096^{\prime \prime} 0$ e altitude $747 \mathrm{~m}$. No período de experimentação, a precipitação pluviométrica na região foi de $40 \mathrm{~mm}$, com temperatura ambiente média de 28ㅇ (INMET 2012). 0 período de adaptação foi de 28 dias em currais de confinamento com dimensões de $10 \mathrm{~m}$ x $10 \mathrm{~m}$ e área de $10 \mathrm{~m}^{2}$ por animal, contendo cochos cobertos e bebedouros artificiais. A alimentação era oferecida duas vezes ao dia, sendo constituída de silagem de milho, ração concentrada e mistura mineral. Por último, realizou-se o abate em frigorífico sob Inspeção Federal e as extremidades distais dos membros torácicos e pélvicos, desarticulados nas junções carpo-metacárpica e tarso-metatársica, foram encaminhados para realizar a morfometria digital no Setor de Patologia da EVZ-UFG.

Nas avaliações empregaram-se dois membros locomotores de cada animal escolhidos por sorteio. Foram sorteados os membros, torácico e pélvico direitos. Os dois membros locomotores restantes, pélvico e torácico esquerdos, foram utilizados em outros estudos. Desta forma, foram examinados 80 membros locomotores e os quatro dígitos de cada animal, distribuídos entre bovinos e bubalinos, totalizando 320 dígitos. As medidas morfométricas foram obtidas com auxílio de um paquímetro mecânico graduado (King Tools), com $300 \mathrm{~mm}$ x 0,05 mm e os ângulos das pinças conferidos por meio de transferidor metálico (Protractor), com ângulos de $0^{\circ} \mathrm{a}$ 
$180^{\circ}$. Os principais parâmetros digitais avaliados foram o ângulo dorsal do casco (A), comprimento da parede dorsal (B), altura do talão $(C)$, altura da pinça (D), comprimento do casco (E), comprimento diagonal do casco $(F)$, largura do dígito lateral $(G)$, largura do dígito medial $(\mathrm{H})$, comprimento do dígito lateral (I) e comprimento do dígito medial (J), totalizando dez medidas por casco (Fig.1A,B).

As mensurações obtidas dos animais alocados em cada grupo foram comparadas pela análise de variância, seguido pelo teste de comparações múltiplas de Tukey $(\mathrm{p} \leq 0,05)$ (Sampaio 2008). A análise multivariada para as representações gráficas das variáveis canônicas foi empregada para expressar a similaridade das variáveis estudadas entre os grupos. Para essas análises utilizou-se o software R (R Development Core Team 2011). 0 peso médio obti-

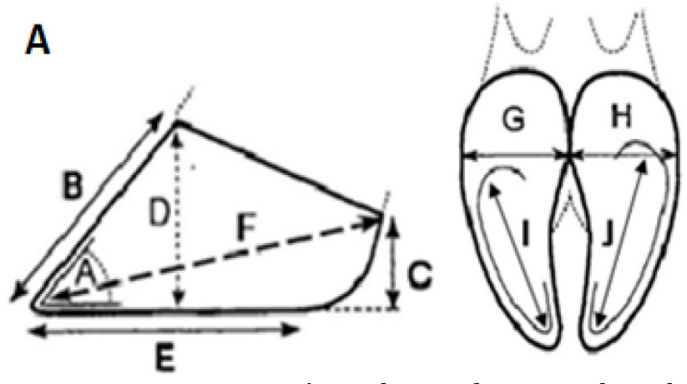

B

Fig.1. Representação esquemática da morfometria digital em bovinos e bubalinos. (A) Vista lateral do dígito mostrando o ângulo dorsal do casco (A); comprimento da parede dorsal (B); altura do talão (C); altura da pinça (D); comprimento do casco (E); comprimento diagonal do casco (F). (B) Vista da sola do casco indicando a largura do dígito lateral (G); comprimento do dígito medial $(\mathrm{H})$; comprimento do dígito lateral (I);(J) comprimento do dígito medial (J). Fonte: adaptado de Vermunt \& Greenough (1995).

do ao final do experimento de cada grupo de bovinos e bubalinos (GI, GII, GIII e GIV) foi analisado para estabelecer uma possível correlação entre as medidas dos dígitos e o porte dos animais empregados no experimento. Nesta avaliação empregou-se estatística descritiva (Sampaio 2008).

\section{RESULTADOS}

Os valores médios, erros padrão e coeficientes de variação obtidos das mensurações realizadas nos dígitos, lateral (L) e medial (M) dos membros torácicos e pélvicos direitos de bovinos das raças Nelore, Pantaneira e Curraleira e bubalinos da raça Murrah, estão dispostos nos Quadros 1 e 2, respectivamente. Amostras de diferentes grupos estão apresentadas na Figura 2.

0 ângulo dorsal dos cascos (A) não mostrou diferença $(p>0,05)$ nos membros torácicos em todas as raças de bovinos e nos bubalinos. Nos membros pélvicos, nos dígitos mediais, os bubalinos apresentaram menor ângulo em relação aos bovinos. Nos dígitos laterais, os bovinos da raça $\mathrm{Ne}$ lore apresentaram maior média. Houve similaridade entre os animais da raça Pantaneira, Curraleira e os bubalinos, os quais apresentaram menor média.

Houve diferença $(\mathrm{p} \leq 0,05)$ entre o comprimento da parede dorsal (B) no dígito medial do membro pélvico nos animais da raça Pantaneira, Curraleira e os bubalinos, além de similaridade entre búfalos e Nelores. No dígito lateral e nos dígitos do membro pélvico os bubalinos demonstra-
Quadro 1. Valores médios em centímetros (B, C, D, E, F, G, H, $\mathrm{I}, \mathrm{J})$, graus (A) e desvios padrão das medidas realizadas no casco dos dígitos lateral e medial, dos membros torácicos de bovinos das raças Nelore, Pantaneira, Curraleira e da espécie Bubalina. Goiânia, 2012

\begin{tabular}{|c|c|c|c|c|c|c|c|}
\hline \multirow{2}{*}{$\begin{array}{l}\text { Mem- } \\
\text { bro }\end{array}$} & \multirow{2}{*}{\multicolumn{2}{|c|}{$\begin{array}{l}\text { Dí- Variá- } \\
\text { gito veis }\end{array}$}} & \multicolumn{4}{|c|}{ Grupos } & \multirow[t]{2}{*}{$\mathrm{CV}(\%)$} \\
\hline & & & Nelores & Pantaneiros & Curraleiros & Búfalos & \\
\hline \multirow{16}{*}{ 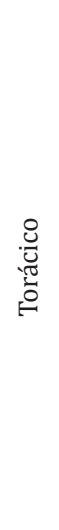 } & \multirow{8}{*}{ 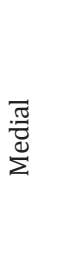 } & A & $54,9 \pm 4,76^{a}$ & $4,3 \pm 6,67^{a}$ & $54,6 \pm 3,6^{a}$ & $54 \pm 15,77^{a}$ & 0,61 \\
\hline & & B & $8,18 \pm 0,21^{a}$ & $7,69 \pm 0,39^{\text {ab }}$ & $7,23 \pm 0,55^{b}$ & $8,97 \pm 1,16^{\mathrm{ac}}$ & 8,03 \\
\hline & & $\mathrm{C}$ & $4,07 \pm 0,16^{a}$ & $3,99 \pm 0,25^{\mathrm{a}}$ & $3,55 \pm 0,22^{\mathrm{a}}$ & $5,11 \pm 0,53^{b}$ & 13,69 \\
\hline & & D & $6,64 \pm 0,26^{a}$ & $6,24 \pm 0,19^{a}$ & $5,81 \pm 0,18^{a}$ & $8,11 \pm 1,36^{\mathrm{b}}$ & 12,91 \\
\hline & & E & $10,14 \pm 0,68^{a}$ & $9,98 \pm 0,87^{a}$ & $8,88 \pm 1,11^{\mathrm{a}}$ & $12,21 \pm 3,07^{b}$ & b 11,76 \\
\hline & & $\mathrm{F}$ & $13,44 \pm 0,33^{a}$ & $13,07 \pm 0,32^{\mathrm{ab}}$ & $11,84 \pm 0,58^{b}$ & $15,98 \pm 4,43$ & c 11,08 \\
\hline & & $\mathrm{H}$ & $5,09 \pm 0,17^{a}$ & $4,92 \pm 0,07^{a}$ & $4,66 \pm 0,06^{\mathrm{a}}$ & $6,49 \pm 1,15^{\mathrm{b}}$ & 13,41 \\
\hline & & $\mathrm{J}$ & $8,97 \pm 0,14^{\mathrm{a}}$ & $8,71 \pm 0,40^{\mathrm{ab}}$ & $7,89 \pm 0,22^{\mathrm{b}}$ & $9,9 \pm 1,51^{\mathrm{c}}$ & 8,08 \\
\hline & \multirow{8}{*}{ 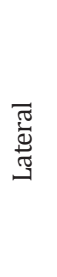 } & A & $55,4 \pm 2,48^{a}$ & $55,3 \pm 5,12^{\mathrm{a}}$ & $55 \pm 5,11^{\mathrm{a}}$ & $54,8 \pm 10,4^{\mathrm{a}}$ & 0,43 \\
\hline & & B & $8,07 \pm 0,28^{\mathrm{a}}$ & $7,42 \pm 0,51^{\mathrm{a}}$ & $7,2 \pm 0,47^{a}$ & $8,88 \pm 1,22^{b}$ & 8,28 \\
\hline & & $\mathrm{C}$ & $4,4 \pm 0,17^{a}$ & $3,95 \pm 0,17^{\mathrm{ab}}$ & $3,73 \pm 0,24^{b}$ & $5,39 \pm 0,32^{c}$ & 14,60 \\
\hline & & D & $6,8 \pm 0,44^{\mathrm{a}}$ & $6,48 \pm 0,11^{a}$ & $5,99 \pm 0,24^{a}$ & $8,19 \pm 1,37^{b}$ & 11,90 \\
\hline & & E & $9,86 \pm 0,70^{\mathrm{a}}$ & $9,65 \pm 0,74^{\text {ab }}$ & $8,83 \pm 0,69^{b}$ & $11,92 \pm 1,96^{c}$ & c 11,30 \\
\hline & & $\mathrm{F}$ & $13,64 \pm 0,40^{2}$ & $13,1 \pm 0,34^{\mathrm{ab}}$ & $11,86 \pm 0,66^{b}$ & $16,02 \pm 5,45^{c}$ & c 11,06 \\
\hline & & G & $5,48 \pm 0,10^{a}$ & $5,15 \pm 0,09^{a}$ & $4,93 \pm 0,09^{a}$ & $6,8 \pm 1,04^{\mathrm{b}}$ & 12,97 \\
\hline & & I & $8,61 \pm 0,11^{a}$ & $8,51 \pm 0,44^{a}$ & $7,74 \pm 0,37^{a}$ & $9,69 \pm 1,82^{b}$ & 8,04 \\
\hline
\end{tabular}

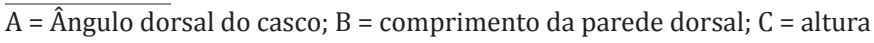
do talão; $\mathrm{D}=$ altura da pinça; $\mathrm{E}=$ comprimento do casco; $\mathrm{F}=$ comprimento diagonal do casco; $\mathrm{G}=$ largura do dígito lateral; $\mathrm{H}=$ comprimento do dígitomedial; $\mathrm{I}$ = comprimento do dígito lateral. $\mathrm{J}$ = comprimento do dígito medial. Médias seguidas por letras minúsculas diferentes na mesma linha diferem pelo teste de Tukey $(\mathrm{p} \leq 0,05)$. Comparação válida entre grupos (Nelore, Curraleira, Pantaneira e a espécie Bubalina). CV (\%) = Coeficiente de Variação expresso em percentagem.

Quadro 2. Valores médios em centímetros (B, C, D, E, F, G, H, I, J) e graus (A); desvio padrão das medidas realizadas no casco dos dígitos lateral e medial, dos membros pélvicos de

bovinos das raças Nelore, Pantaneira, Curraleira e da espécie Bubalina. Goiânia, 2012

\begin{tabular}{|c|c|c|c|c|c|c|c|}
\hline \multirow{2}{*}{$\begin{array}{l}\text { Mem- } \\
\text { bro }\end{array}$} & \multirow{2}{*}{$\begin{array}{l}\text { Dí- } \\
\text { gito }\end{array}$} & \multirow{2}{*}{$\begin{array}{l}\text { Variá- } \\
\text { veis }\end{array}$} & \multicolumn{4}{|c|}{ Grupos } & \multirow[t]{2}{*}{$\mathrm{CV}(\%)$} \\
\hline & & & Nelores & Pantaneiros & Curraleiros & Búfalos & \\
\hline \multirow{16}{*}{ 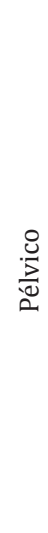 } & \multirow{8}{*}{$\begin{array}{l}\frac{\pi}{\pi} \\
\stackrel{0}{\Sigma}\end{array}$} & A & $55,9 \pm 2,54^{\mathrm{a}}$ & $54,6 \pm 1,82^{\mathrm{a}}$ & $55,4 \pm 5,15^{\mathrm{a}}$ & $51,4 \pm 16$ & 3,22 \\
\hline & & B & $7,67 \pm 0$, & $7,26 \pm 0,38^{\mathrm{a}}$ & $6,79=$ & 9,12 & 11,30 \\
\hline & & C & $3,42 \pm 0,43^{\mathrm{a}}$ & $3,47 \pm 0,17^{\mathrm{a}}$ & $3,26 \pm 0,30^{\mathrm{a}}$ & $4,58 \pm 4,05^{\mathrm{a}}$ & 14,22 \\
\hline & & D & $6,04 \pm 0,22^{\mathrm{a}}$ & $5,84 \pm 0,26^{a}$ & $5,59 \pm 0,28^{\mathrm{a}}$ & $7,51 \pm 2,26^{b}$ & 11,97 \\
\hline & & E & $9,39 \pm 1,08^{a}$ & $8,7 \pm 0,72^{\mathrm{ab}}$ & $7,64 \pm 0,59^{b}$ & $11,46 \pm 1,64^{c}$ & c 15,00 \\
\hline & & $\mathrm{F}$ & $12,32 \pm 0,49$ & $a 11,73 \pm 0,57^{a b}$ & $10,61 \pm 0,35^{b}$ & $14,3 \pm$ & 10,93 \\
\hline & & $\mathrm{H}$ & $4,76 \pm 0,06^{a}$ & $4,67 \pm 0,09^{a}$ & $4,43 \pm 0,05^{\mathrm{a}}$ & $5,78 \pm 0,49^{b}$ & 10,52 \\
\hline & & $\mathrm{J}$ & $7,88 \pm 0,22^{\mathrm{a}}$ & $7,75 \pm 0,07^{\mathrm{ab}}$ & $7,04 \pm 0,20^{\mathrm{b}}$ & $9,18 \pm 0,90^{c}$ & 9,69 \\
\hline & \multirow{8}{*}{ 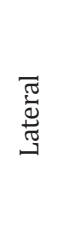 } & A & $56,7 \pm 4,01^{\mathrm{a}}$ & $54 \pm 13,77^{\mathrm{ab}}$ & $55,8 \pm 2,62^{\mathrm{ab}}$ & $52,3 \pm 16,23^{b}$ & b 3,09 \\
\hline & & B & $7,49 \pm 0,10^{\mathrm{a}}$ & $7,27 \pm 0,34^{\mathrm{a}}$ & $6,64 \pm 0,37^{\mathrm{a}}$ & $8,88 \pm 1,14^{\mathrm{b}}$ & 10,80 \\
\hline & & C & $3,63 \pm 0,31^{\mathrm{a}}$ & $3,42 \pm 0,16^{\mathrm{a}}$ & $3,26 \pm 0,12^{\mathrm{a}}$ & $4,76 \pm 4,06^{\mathrm{ab}}$ & 15,60 \\
\hline & & D & $6,21 \pm 0,11^{\mathrm{a}}$ & $6,02 \pm 0,28^{a}$ & $5,59 \pm 0,23^{a}$ & $7,39 \pm 1,88^{b}$ & 10,58 \\
\hline & & E & $9,35 \pm 0,73^{\mathrm{a}}$ & $9,04 \pm 1,31^{a}$ & $7,63 \pm 0,54^{b}$ & $11,53 \pm 2,13^{c}$ & c 14,87 \\
\hline & & $\mathrm{F}$ & $12,08 \pm 0,17$ & a $11,95 \pm 0,85^{\text {a }}$ & $10,54 \pm 0,36^{b}$ & $14,62 \pm 3,15^{c}$ & c 11,95 \\
\hline & & G & $4,63 \pm 0,14^{\mathrm{a}}$ & $4,64 \pm 0,13^{\mathrm{a}}$ & $4,33 \pm 0,62^{\mathrm{a}}$ & $6 \pm 0,55^{b}$ & 14,57 \\
\hline & & I & $7,52 \pm 0,24^{a}$ & $7,92 \pm 0,70^{\mathrm{a}}$ & $7,01 \pm 0,33^{\mathrm{a}}$ & $9 \pm 1,64^{\mathrm{b}}$ & 9,30 \\
\hline
\end{tabular}

$\mathrm{A}=$ Ângulo dorsal do casco; $\mathrm{B}=$ comprimento da parede dorsal; $\mathrm{C}=$ altura do talão; $\mathrm{D}=$ altura da pinça; $\mathrm{E}=$ comprimento do casco; $\mathrm{F}=$ comprimento diagonal do casco; $\mathrm{G}=$ largura do dígito lateral; $\mathrm{H}=$ comprimento do dígito medial; $\mathrm{I}$ = comprimento do dígito lateral; $\mathrm{J}=$ comprimento do dígito medial. Médias seguidas por letras minúsculas diferentes na mesma linha diferem pelo teste de Tukey $(\mathrm{p} \leq 0,05)$. Comparação válida entre grupos (raças, Nelore, Curraleira, Pantaneira e a espécie bubalina). CV $(\%)=$ Coeficiente de Variação expresso em percentagem.

ram diferença significativa ao comparar estas medidas às demais raças de bovinos.

A altura do talão (C) do dígito torácico medial foi maior 


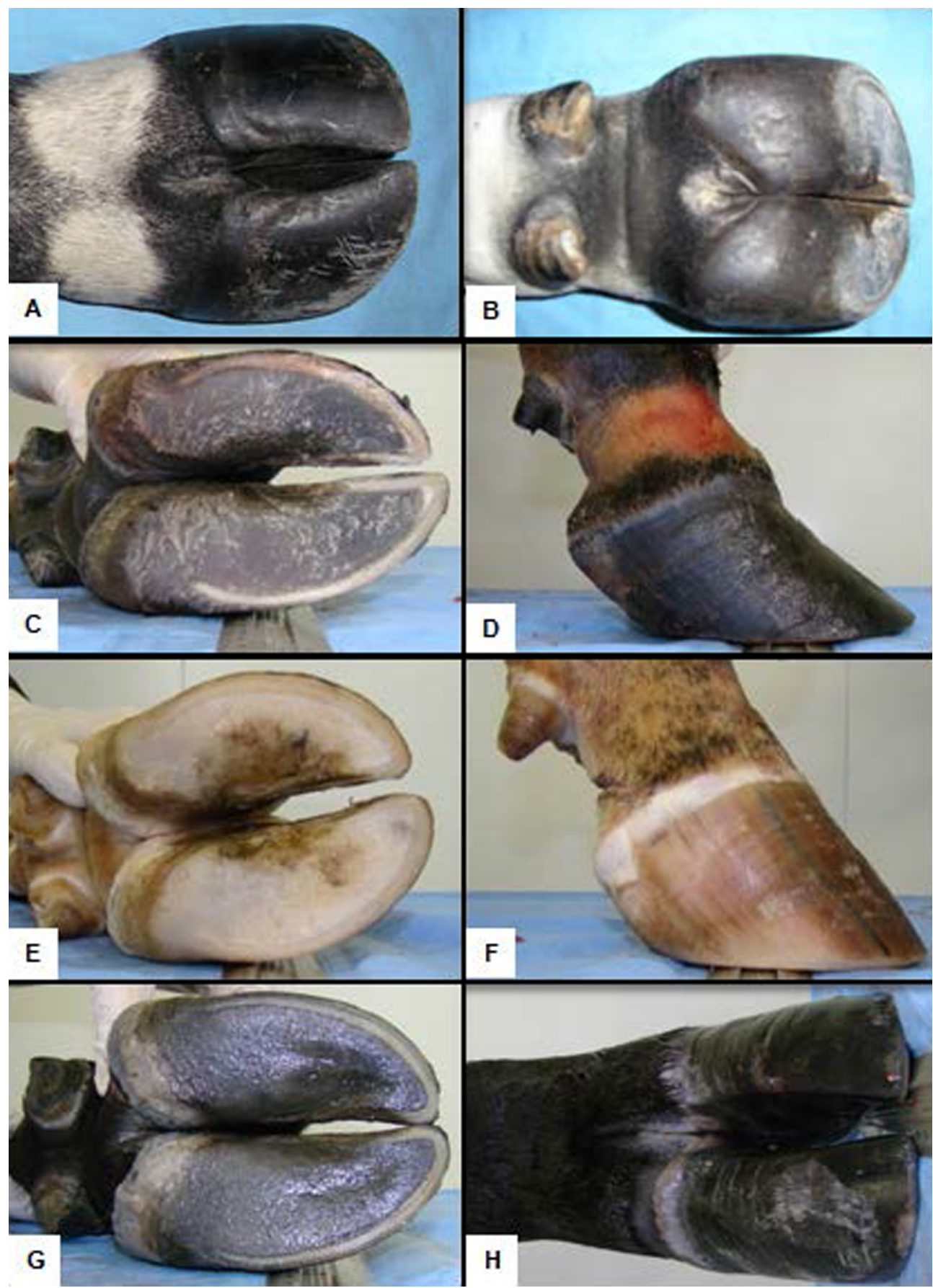

Fig.2. Amostras de dígitos de membro torácico de diferentes raças. Vista dorsal do dígito de bovino da raça Nelore (A), vista palmar do dígito de bovino da raça Nelore (B), vista solear do dígito de bovino da raça Curraleira (C), vista lateral do dígito de bovino da raça Curraleira (D), vista solear do dígito de bovino da raça Pantaneira (E), vista lateral do dígito de bovino da raça Pantaneira (F), vista solear do dígito de bubalino da raça Murrah (G), vista dorsal do dígito de bubalino da raça Murrah (H).

entre os bubalinos $(\mathrm{p} \leq 0,05)$ quando se comparou com as demais raças de bovinos, mas não houve diferença entre as raças de bovinos. 0 dígito lateral do membro torácico diferiu entre os bovinos da raça Curraleira, Pantaneira e os búfalos. Contudo, houve similaridade entre as raças Curraleira e Pantaneira. Não houve diferença entre os animais nas medidas do dígito medial do membro pélvico. Mas no dígito lateral, os bubalinos apresentaram maior medida que os bovinos. A altura da pinça (D) dos bubalinos apresentou maior medida nos quatro dígitos, diferindo dos bovinos de todas as raças $(\mathrm{p} \leq 0,05)$.

O comprimento do casco (E) dos bubalinos foi maior nos dígitos mediais dos membros torácicos e pélvicos. No dígito lateral torácico houve diferença $(\mathrm{p} \leq 0,05)$ entre os animais da raça Curraleira, Pantaneira e bubalinos. Já no dígito lateral pélvico houve diferença entre os animais da raça Curraleira e búfalos, sendo os bubalinos os animais com maior comprimento do casco.

Houve diferença $(\mathrm{p} \leq 0,05)$ no comprimento diagonal do casco (F) entre os bovinos da raça Curraleira, Pantaneira e 

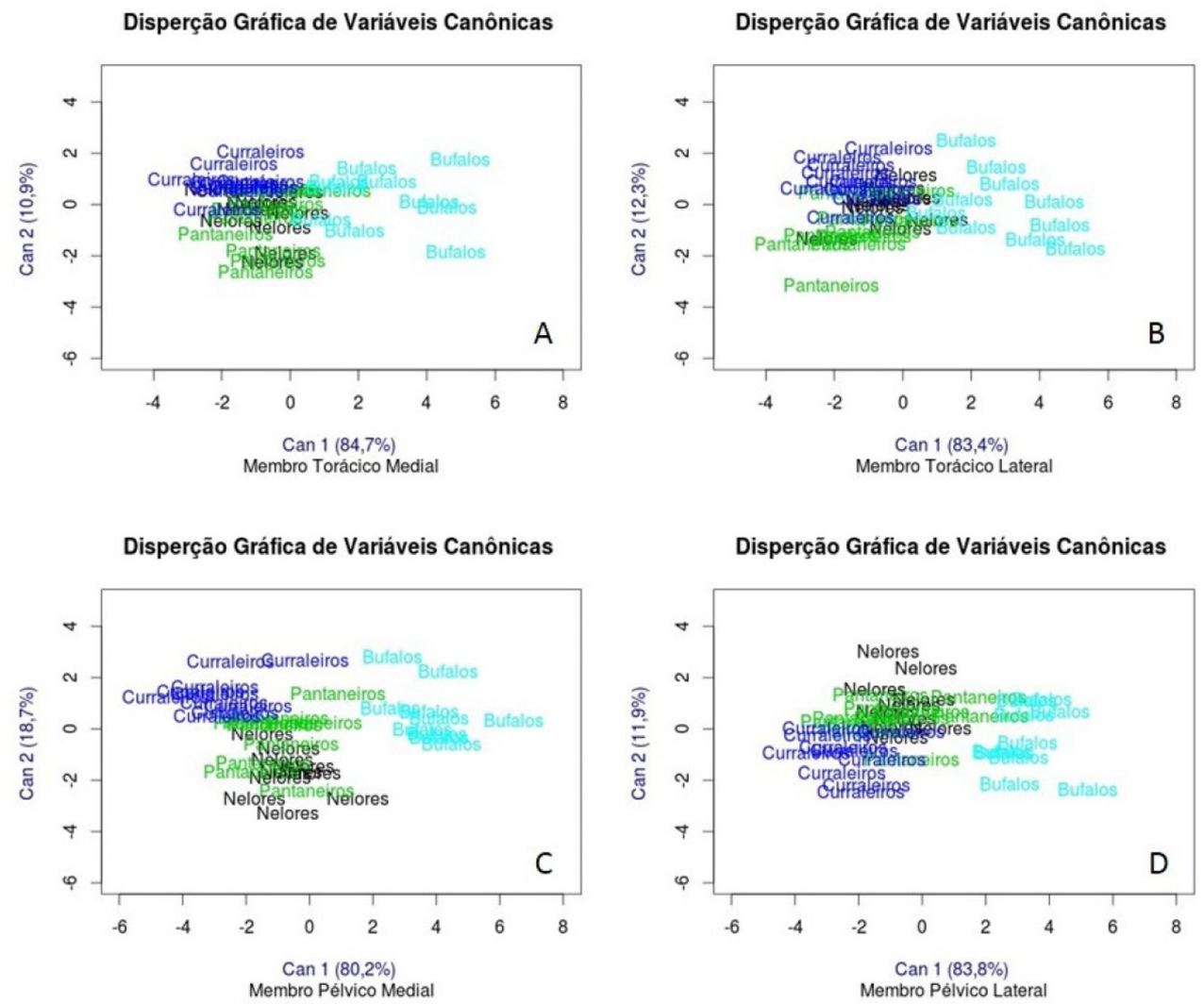

Fig.3. Representações gráficas das variáveis canônicas obtidas utilizando as variáveis mensuradas nos membros torácicos dígitos mediais (A), membros torácicos dígitos laterais (B), membros pélvicos dígitos mediais (C) e membros pélvicos dígitos laterais (D) para os grupos: Nelore (preto), Pantaneira (verde), Curraleira (azul escuro) e búfalos (azul claro).

búfalos para as medidas dos dígitos, torácico medial e lateral e, pélvico medial. No dígito pélvico lateral apenas os bubalinos diferiram dos outros animais. 0 comprimento do dígito lateral (I) foi maior nos membros torácicos em relação aos pélvicos, sendo comprovada diferença $(p \leq 0,05)$ apenas no grupo dos bubalinos com relação aos três grupos de bovinos. Já o comprimento do dígito medial (J) indicou diferenças entre os animais da raça Curraleira, Pantaneira e búfalos. A largura do dígito lateral (G) e a largura do dígito medial $(H)$ foram similares $(p>0,05)$ entres as três raças de bovinos. Os bubalinos apresentaram a maior medida dos grupos.

A similaridade das variáveis analisadas entre as raças de bovinos e búfalos com relação às medidas aferidas nos dígitos estão dispostos na representação gráfica ilustrada na Figura 3A-D. No membro torácico (Fig.3A,B) a distribuição dos animais em relação às variáveis analisadas indica maior similaridade entre bovinos da raça Curraleira (azul escuro), Nelore (preto) e Pantaneira (verde). Nos membros pélvicos (Fig.3C e D), a similaridade também ocorreu entre essas raças. Os búfalos (azul claro) foram os animais que mais apresentam disparidade entre as medidas, quando comparadas com as raças bovinas estudadas.

\section{DISCUSSÃO}

Durante todo o período da pesquisa, incluindo os 28 dias de adaptação, somados aos 120 dias de confinamento, não foram observadas quaisquer afecções podais nos animais dos quatro Grupos experimentais indicando que algum fator pode ter minimizado a ocorrência do problema. Portanto, mesmo que não tenha encontrado na literatura disponível análises comparativas entre os bovinos das raças, Nelore, Pantaneira e Curraleira e os bubalinos, não se pode negligenciar que determinadas características digitais possam ser valorizadas nos processos de seleção e resultar em animais mais resistentes as lesões digitais.

Mas, ainda que observações diárias indiquem que bovinos das raças Curraleira e Pantaneira e que os bubalinos são animais considerados mais resistentes às enfermidades digitais é necessário aprofundar o estudo para comprovar tal fato. Assim, ponderando-se sobre a raça Nelore, observa-se que mesmo em criatórios extensivos, os avanços impostos pelo melhoramento genético, em tese, têm contribuído para aumentar a ocorrência de enfermidades nos dígitos dos animais dessa raça. Portanto, diante da complexidade do tema, mesmo que os resultados obtidos no presente estudo contribuam para a seleção de animais resistentes às doenças podais, certamente a aplicação dos benefícios auferidos pela pesquisa, será um processo lento. Contudo, não se pode ignorar a possibilidade de a morfometria digital ser um fator de risco para as doenças digitais e contribuir para a gênese multifatorial de tais enfermidades. Raven (1985), Vermunt \& Greenough (1995), Mendonça et al. (2003), Dirksen et al. (2005), Greenough (2007) e Lima (2011) consideraram as medidas morfométricas um fator de risco para as enfermidades podais nos bovinos. 
A ausência de informações científicas confrontando medidas digitais entre as três raças de bovinos avaliadas e a espécie bubalina indica o pioneirismo da pesquisa desenvolvida. Nessas circunstâncias, os valores encontrados poderão compor um banco de dados para análises comparativas futuras com outras raças de bovinos menos resistentes as enfermidades digitais. Vermunt \& Greenough (1995), Greenough (2007), Lima et al. (2013) e Túlio (2006), adotaram, respectivamente, procedimentos semelhantes para aferirem os dígitos de bovinos e bubalinos de diferentes idades. Mendonça et al. (2003) apontaram diferenças entre as medidas digitais obtidas para bovinos da raça Holandesa e Gir em diferentes idades. Os autores destacaram que as medidas referentes à altura do talão, ângulo dorsal e comprimento da parede dorsal do casco encontradas para a raça Gir sugerem que o aprumo e a distribuição do peso são favorecidos nessa raça, minimizando a ocorrência de enfermidades podais.

Ao realizar uma análise geral sobre os parâmetros avaliados, pode-se inferir que o valor obtido para as medidas do ângulo dorsal (A), comprimento da parede dorsal (B) e altura do talão $(\mathrm{C})$ podem ter alguma relação com a menor predisposição a determinadas enfermidades digitais em bovinos das raças, Pantaneira e Curraleira. Sobre essa possibilidade deve-se ponderar que esses animais são manejados em regiões distintas, a Pantaneira na região do pantanal mato-grossense com grandes áreas de pântanos e lagos. A Curraleira, ao contrário, em regiões áridas do cerrado brasileiro contendo solo arenoso ou com cascalho. Confrontando tais valores com os achados de Túlio (2006), verifica-se que as medidas externas do casco dessas raças são semelhantes às encontradas para os animais da raça Jersey e da espécie bubalina. A primeira apresentando maior ocorrência de enfermidades digitais que a segunda, cujo habitat preferido são regiões de lagos e pântanos. Assim, fazendo uma análise geral dos resultados, supõe-se que determinadas medidas digitais não são suficientes para desencadear doenças digitais quando se apresentam de forma isolada.

Embora a morfometria digital das três raças de bovinos e da espécie bubalina, isoladamente, não seja suficiente para justificar a maior ou menor ocorrência de enfermidades digitais, os achados abrem um horizonte para a implementação de pesquisas científicas envolvendo melhoramento animal. Ao valorizar alguns desses parâmetros nos cruzamentos entre raças, os resultados poderão auxiliar na maximização e perpetuação de características digitais desejáveis na prevenção e controle de doenças digitais. Ainda assim, é preciso analisar outros fatores relacionados à maior ou menor resistência dos bovinos e bubalinos às enfermidades digitais. Apesar de a literatura ser exígua, a avaliação ultraestrutural das papilas dérmicas e túbulos córneos, incluindo o número, comprimento, diâmetro e a distância entre estas estruturas do casco podem representar um avanço no estudo da produção de queratina pelo estojo córneo. Portanto, justificando, em parte, o fato de algumas raças e espécies serem mais vulneráveis as doenças digitais. Rabbers et al. (2013) associaram variações no número de papilas dérmicas a melhor qualidade do casco.
Outros achados ultraestruturais como a quantidade de queratinócitos e de seus desmossomos e o número de tonofilamentos existentes na epiderme coronária, bem como o diâmetro dos túbulos de queratina na parede do casco citados por Greenough (2007) também podem ser importantes no estudo da etiopatogenia das enfermidades digitais. Além destes fatores e de acordo com Bragulla \& Homberger (2009), não só os achados ultraestruturais, mas os diferentes tipos de moléculas de queratina, a composição da queratina, natureza bioquímica e a sua microarquetetura, são fatores que influênciam na dureza do tecido. Portanto, pode influenciar na porosidade do casco tornando-o mais susceptível aos problemas digitais. Isso fortalece a possibilidade de alguns fatores de risco envolvidos na etiopatogenia das enfermidades digitais dos bovinos ainda permanecerem desconhecidos. Demirkan et al. (2000), Mendonça et al. (2003), Leão (2006), Blowey (2008) e Lima et al. (2009) sugeriram a necessidade de aprofundar os estudos envolvendo a morfometria e histologia digital na tentativa de justificar a ocorrência de doenças podais.

Não só estudos, morfométrico e histológicos, devem ser realizados, mas algum que envolva o reações químicas, pois já foi citado por Devlin (2007) que existem possibilidades de reações químicas para formação e destruição de cadeias moleculares, por meio de interação entre elementos e ligações moleculares. Como exemplo pode-se citar a interação do elemento oxigênio no comprometimento da integridade das pontes dissulfeto. Segundo Nelson \& Cox (2011), as pontes dissulfeto são as únicas ligações cruzadas de cadeia lateral covalentes encontradas nas proteínas. Elas podem ocorrer tanto intramolecular como intermolecularmente. Nas proteínas monoméricas, as pontes dissulfeto são formadas como resultado do dobramento de proteínas. Quando os resíduos de cisteína ficam próximos um do outro, com orientação apropriada a oxidação de grupos sulfidrila pelo oxigênio molecular resulta em formação de pontes dissulfeto. Uma vez formadas, elas ajudam a estabilizar a estrutura dobrada das proteínas. Misturas proteicas que contem resíduos de cistina e de cisteína são capazes de sofrer reações de troca sulfidril-dissulfeto. A reação de troca também pode ocorrer dentro de uma única proteína desnaturada se ela contiver um grupo sulfidril livre e uma ponte dissulfeto. Essa reação costuma levar à diminuição de estabilidade da molécula proteica.

Reações bioquímicas envolvendo microelementos que compõe o estojo córneo como o enxofre, hidrogênio e oxigênio, comprometendo as pontes de dissulfeto, podem ocorrer, interferindo na síntese de queratina. Assim, considerando o habitat dos animais da raça Pantaneira e bubalinos, geralmente portadores de cascos pigmentados, é possível que a umidade e, presença de oxigênio oriundo da água, exerça menor influência sobre a morfometria, resistência, diferenciação e susceptibilidade desses animais às doenças digitais quando comparados a bovinos portadores de cascos despigmentados. Mas, além desses mecanismos outros fatores ainda necessitam ser melhor investigados. Ainda ponderando sobre o assunto, não se pode ignorar a pigmentação, pois cascos despigmentados tendem a ser mais hidrofílicos quando comparados aos pigmentados. 
Este fato pode estar relacionado com a melanina apresentar propriedades antioxidantes, criando um ambiente químico redutor que influencia na dureza do casco, como citado nos estudos de Hepburn, Kinninmonth \& Galbraith (2007).

Ponderando sobre a complexidade do assunto e os achados aqui observados, verifica-se que as maiores medidas notadas para as variáveis B, C, D, E, F, G, H, I e J aferidas nos dígitos dos bubalinos sugerem algumas particularidades importantes que podem justificar a menor ocorrência de enfermidades digitais nessa espécie animal, apesar de coabitar regiões de pântanos. Mas, analisando separadamente o ângulo dorsal do casco (A) verifica-se que o valor obtido foi menor quando comparado com as três raças de bovinos estudadas, portanto, conferindo à espécie bubalina um casco com formato mais achatado. Esse formato pode indicar que houve adaptações contínuas para permitir a locomoção em lagos e ambientes pantanosos e não ser um fator de risco determinante para as enfermidades digitais. Ainda sobre o ângulo dorsal do casco, a aparente similaridade entre os animais das raças, Pantaneira e Curraleira e os bubalinos não se repetiu quando se comparou com os Nelores, justificando, em parte, segundo Moura (2008), uma ocorrência expressiva de lesões digitais nos animais da raça Nelore. Para Dirksen et al. (2005) a angulação do casco proporciona alterações que predispõe as lesões digitais e Túlio (2006) relacionou o maior peso corporal médio dos bubalinos as maiores medidas dos cascos.

Considerando que as maiores medidas para a parede dorsal (B) do casco dos bubalinos foram encontradas nos membros pélvicos, presume-se que o desgaste do casco nesses membros foi menor que o crescimento. Portanto, ponderando sobre os achados de Mendonça et al. (2003) e Túlio (2006) infere-se que a parede do casco e da região bulbar de animais manejados em superfícies macias afundam-se facilmente no solo. Nessas circunstâncias ocorre menor desgaste do estojo córneo que adquire o formato de aba. Esse formato transfere, em parte, a superfície de sustentação do peso para a região axial. Assim, essa adaptação no formato do casco, devido ao manejo dos bubalinos em ambientes úmidos, pode ter relação com os menores valores encontrados para o ângulo dorsal dessa estrutura atômica digital.

Argumentando sobre a maior altura do talão (C) do dígito torácico medial ter sido identificada nos bubalinos em comparação com as raças Curraleira, Pantaneira e Nelore, acredita-se que pode ser uma medida compensatória para melhorar o desempenho dessa espécie quando manejada em terrenos secos, irregulares e compactados como ocorre em criatórios modernos de bubalinos na região centro-sul do país. Contudo, mesmo que o desempenho dos bubalinos em regiões alagadiças tenha relação com o formato achatado do casco, não se pode relacionar esse achado com a ocorrência de doenças digitais nesses animais, pois essa espécie raramente apresenta enfermidades digitais. Mendonça et al. (2003) relacionaram a maior altura do talão nos animais da raça Gir ao maior apoio com as pinças e menor contato com fezes e umidade, circunstâncias que resultam em menor ocorrência de enfermidades digitais nessa raça de bovinos.
A similaridade observada entre as três raças de bovinos estudadas em relação às variáveis, altura da pinça (D), largura do dígito lateral $(G)$ e largura do dígito medial $(\mathrm{H})$, distanciando dos valores encontrados para essas variáveis nos bubalinos, reforça que o maior rebaixamento do casco nessa espécie proporciona maior desempenho dos animais em áreas alagadiças. Acredita-se que formato mais largo e a maior altura dos cascos são características adaptativas importantes para que estes não afundem na lama ao se locomoverem e ajudem a impulsioná-los nas áreas de várzea. Ao ponderar sobre os achados relacionados às medidas de comprimento do casco (E), comprimento diagonal do casco (F), comprimento do dígito lateral (I) e comprimento do dígito medial (J) verifica-se que houve grande disparidade de achados entre os dígitos, das três raças e da espécie estudada, inferindo-se que estas medidas morfométricas, isoladamente, não sejam tão importantes na seleção de animais visando desenvolver animais mais resistentes as enfermidades digitais. Greenough (2007) sugeriram que a maior altura da pinça (D) e a maior largura do dígito lateral (G) e do dígito medial $(\mathrm{H})$ podem ser indesejáveis para animais manejados em pisos duros e abrasivos.

Outro aspecto anatômico provavelmente relevante, mas não avaliado no presente estudo, na maior ou menor ocorrência de lesões podais é a relação de comprimento entre os dedos III e IV. Muggli et al. (2011) observaram assimetria entre os dedos III e IV (IV maior) em membros pélvicos e torácicos porém, com assimetria mais acentuada para os pélvicos. Segundo os autores esse pode ser um dos fatores que ajude a explicar a maior incidência de lesões podais nos membros pélvicos. Para Nourinezhad et al. (2012),a similaridade entre a medida dos ossos dos dígitos medial e lateral do membro pélvico pode justificar a menor ocorrência de lesões biomecanicas nos bubalinos quando comparado aos bovinos.

Os gráficos de similaridade resultantes das análises canônicas demonstraram maior proximidade entre as medidas digitais de bovinos das raças Nelore (GI), Pantaneira (GII) e Curraleira (GIII) e alguma proximidade entre os bovinos da raça Pantaneira (GII) e a espécie bubalina (GIV). Considerando-se que os animais dessa raça e da espécie analisada, geralmente são manejados ou preferem regiões alagadiças, os achados podem estar relacionados à adaptação das estruturas digitais desses animais para se locomoverem em regiões com muita lama e água. A disparidade entre as medidas de todos os bovinos analisados e a similaridade existente entre a raça Pantaneira e a espécie bubalina indica a complexidade do assunto e sugere-se que existem outros fatores relacionados ao casco que limitam a ocorrência de enfermidades digitais nessa raça e espécie. Mesmo assim, o estudo da morfometria digital aqui realizado pode ser importante em trabalhos de melhoramento genético, favorecendo a seleção de animais geneticamente superiores quanto a resistência as enfermidades digitais. Dentre os benefícios auferidos, o estimulo a produção de animais com maior área de apoio digital ao solo em relação ao peso corporal, especialmente envolvendo bovinos de alto mérito genético, superalimentados e mantidos em pisos compactados por longos períodos, não podem ser desconsiderados. 


\section{CONCLUSÕES}

A morfometria digital pode influenciar na ocorrência de enfermidades digitais, mas não age como fator isolado, necessitando da interação com outros fatores estruturais, ambientais e de manejo para a manifestação dessas doenças.

As diferenças observadas na morfometria dos dígitos de bubalinos e bovinos podem ajudar a explicar a menor ocorrência de doenças digitais nos bubalinos.

\section{REFERÊNCIAS}

Archer S., Bell N. \& Huxley J.N. 2010. Lameness in UK dairy cows: a review of the current status. In Practice. 32: 492-504.

Blowey R.W. 2008. Claudicações, p.362-384. In: Andrews A.H., Blowey R.W., Boyd H. \& Eddy R.G. (Eds), Medicina Bovina: doenças e criação de bovinos. 2 a ed. Roca, São Paulo, SP.

Bragulla H.H. \& Homberger D.G. 2009. Structure and functions of keratin proteins in simple, stratified, keratinized and cornified epithelia. J. Anat. 214:516-559.

Devlin T.M. 2007. Manual de Bioquímica com Correlações Clínicas. $6^{a}$ ed. Editora Blucher, São Paulo, SP.

Demirkan I., Murray R.D. \& Carter S.D. 2000. Skin diseases of the bovine digit associated with lameness. Vet. Bull. 70:149-171.

Dirksen G., Gründer H.D. \& Stöber M. 2005. Medicina Interna y Cirugía del Bovino. 4a ed. Inter-Médica Editorial, Buenos Aires. 1172p.

Greenough P.R. 2007. Bovine Laminitis and Lameness - A hands-on Approach. Saunders Elsevier, Philadelphia. 311 p.

Hepburn N.L., Kinninmonth L. \& Galbraith H. 2007. Pigmentation, impression hardness and the presence of melanosomes in bovine claw tissue. J. Agricult. Sci. 145:283-290.

Huxley J.N. 2012. Lameness in cattle: an ongoing concern. Vet. J. 193: 610611.

IBGE 2012. Instituto Brasileiro de Geografia e Estatística. Disponível em <http://www.ibge.gov.br> Acesso em 11 dez. 2012.

INMET 2012. Instituto Nacional de Meteorologia. Disponível em <http:// www.inmet.gov.br> Acesso em 11 dez. 2012.

Leão M.A. 2006. Aspectos epidemiológicos, evolução clínica e controle da dermatite digital em duas propriedades de exploração leiteira no Estado de Goiás. Tese de Doutorado em Ciência Animal, Universidade Federal de Goiás, Goiânia, G0. 96p.

Lima F.B. 2011. Morfologia e Morfometria dos cascos de bovinos Nelorados. Dissertação de Mestrado em Saúde Animal, Universidade de Brasília, Brasília, DF. 86p.

Lima E.M.M., Borges J.R.J., Lima F.B., Silva F.O.C., Leonardo A.S. \& Barreto-Viana A.R.C. 2013. Morfometria do casco de bovinos nelorados em diferentes sistemas de criação. Biosci. J. 29: 412-418.

Lima I.R., Fonseca A.M., Silva L.H., Costa A.P.A., Silva L.A.F. \& Borges N.C. 2009. Estudo radiográfico das extremidades distais dos membros locomotores de bovinos com claudicação. Anais do VIII Congresso Brasileiro de Buiatria, Belo Horizonte, MG, p.423-429. (Resumo)

Melo D.R. 2005. Dados recentes do agronegócio brasileiro. Revista da UFG [online]. 7:12-26. Disponível em <http://www.proec.ufg.br> Acesso em 11 abr. 2011.

Mendonça A.C., Silva L.A.F., Fioravanti M.C.S., Moraes J.O.R., Almeida C.F., Oliveira K.S., Oliveira M.P. \& Silva L.M. 2003. Aspectos morfológicos dos dígitos de bovinos das raças Gir e Holandesa. Cienc. Anim. Bras. 4:5360 .

Moura M.I. 2008. Características espermáticas de reprodutores nelore com dermatite digital. Dissertação de Mestrado em Ciência Animal, Universidade Federal de Goiás, Goiânia, GO. 100p.

Muggli E., Sauter-Louis C., Braun U. \& Nuss K. 2011. Lenght asymmetry of bovine digits. Vet. J. 188: 195-300.

Nelson D.L. \& Cox M.M. 2011. Princípios de Bioquímica de Lehninger. 5a ed. Editora Artmed, Porto Alegre. 1304p.

Nourinezhad J., Mazaheri Y., Pourmahdi Borujeni M. \& Daneshi M. 2012. Morphometric study on digital bones in native Khuzestan Water Buffaloes (Bubalus bubalis). Bulgarian Journal of Veterinary Medicine. 15: 228-235.

Nuss K., Sauter-Louis C. \& Sigmund B. 2011. Measurements of forelimb claw dimensions in cows using a standardized sole thickness: a post-mortem study. Vet. J. 190: 84-89.

R Development Core Team 2011. A Programming Environment for Data Analysis and Graphics. Version 2.6.0.

Rabbers A.S., Rabelo R.E., Vulcani V.A.S., Sant'ana F.J.F., Helrigel P.A., Batista J.F., Dutra H.T., Lima C.O.R., Rabelo T.H.P. \& Alves P.V.S. 2013. Estudo do desenvolvimento e da microestrutura de cascos de bovinos adultos: avaliação por histomorfometria, microtomografia tridimensional e teste de resistência mecânica. Anais X Congresso Brasileiro de Buiatria, Belém, PA, p.1-5. (Resumo)

Raven E.T. 1985. Cattle Footcare and Claw Trimming. Farming Press Books, Chicago. 127p.

Rodrigues M., Deschk M., Santos G.G.F., Perri S.H.V., Merenda V.R., Hussni C.A., Alves A.L.G. \& Rodrigues C.A. 2013. Avaliação das características do líquido ruminal, hemogasometria, atividade pedométrica e diagnóstico de laminite subclínica em vacas leiteiras. Pesq. Vet. Bras. 33(Supl.1):99106.

Sampaio I.B.M. 2008. Estatística aplicada à experimentação animal. 4ª ed. Fundação de Ensino e Pesquisa em Medicina Veterinária e Zootecnia, Belo Horizonte, MG. 264p.

Silva L.A.F., Silva L.K., Romani A.F., Rabelo R.E., Fioravanti M.C.S., Souza T.M. \& Silva C.A. 2001. Características clínicas e epidemiológicas das enfermidades podais em vacas lactantes do município de Orizona, GO. Ciênc. Anim. Bras. 2:119-126.

Túlio L.M. 2006. Estudo biométrico do casco bovino e bubalino: avaliação de características anátomo-fisiológicas do casco sadio. Dissertação de Mestrado em Ciências Veterinárias, Universidade Federal do Paraná, Curitiba, PR. 97p.

Vermunt J.J. \& Greenough P.R. 1995. Structural characteristics of the bovine claw: horn growth and wear, horn hardness and claw conformation. Brit. Vet. J. 151:157-180. 